\title{
The Tat Protein Enhances CTL Responses and Therapeutic Immunity of Gag-Specific Exosome-Targeted T Cell-Based Gag/Tat-Texo Vaccine in Transgenic HLA-A2 Mice
}

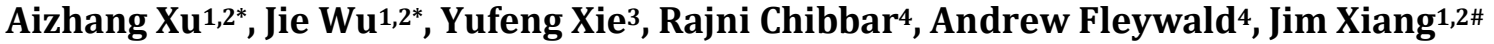 \\ ${ }^{1}$ Cancer Research, Saskatchewan Cancer Agency \\ ${ }^{2}$ Department of Oncology, College of Medicine, University of Saskatchewan, Saskatchewan, Canada \\ ${ }^{3}$ Department of Oncology, The First Affiliated Hospital, Soo Chow University, Suzhou, China \\ ${ }^{4}$ Department of Pathology, College of Medicine, University of Saskatchewan, Saskatchewan, Canada \\ Email: "jim.xiang@usask.ca
}

How to cite this paper: $\mathrm{Xu}, \mathrm{A} . \mathrm{Z}$., Wu, J., Xie, Y.F., Chibbar, R., Fleywald, A. and Xiang, J. (2017) The Tat Protein Enhances CTL Responses and Therapeutic Immunity of Gag-Specific Exosome-Targeted T CellBased Gag/Tat-Texo Vaccine in Transgenic HLA-A2 Mice. World Journal of Vaccines, 7, 11-25.

https://doi.org/10.4236/wjv.2017.72002

Received: September 2, 2016

Accepted: May 24, 2017

Published: May 27, 2017

Copyright $\odot 2017$ by authors and Scientific Research Publishing Inc. This work is licensed under the Creative Commons Attribution International License (CC BY 4.0).

http://creativecommons.org/licenses/by/4.0/

\begin{abstract}
Human immunodeficiency virus type-1 (HIV-1) chronic infection causes millions of deaths each year. We previously developed a novel HIV-1 Gag-spe cific exosome (EXO)-targeted T cell-based vaccine (Gag-Texo) using ConAstimulated polyclonal $\mathrm{CD}^{+} \mathrm{T}$ (ConA-T) cells armed with Gag-specific dendritic cell (DC)-released EXOs, and showed that Gag-Texo stimulated more efficient cytotoxic T lymphocyte (CTL) responses than DCs. Tat HIV-1 early regulatory protein possesses immunomodulatory and adjuvant properties. To enhance Gag-Texo immunogenicity, we generated Tat-engineered OVA/Tat Texo and Gag/Tat-Texo vaccines using ConA-T cells armed with EXOs release by DCs infected with recombinant OVA/Tat- and Gag/Tat-expressing adenoviruses $\left(\mathrm{AdV}_{\mathrm{OVA} / \mathrm{Tat}}\right.$ and $\left.\mathrm{AdV}_{\mathrm{Gag} / \mathrm{Tat}}\right)$. We then assessed vaccination-stimulated CTL responses in naïve mice, and therapeutic immunity in transgenic HLA-A2 mice bearing Gag/HLA-A2-expressing BL6-10 $0_{\mathrm{OVA} / \mathrm{A} 2}$ melanoma lung metastases. We demonstrate that the OVA/Tat-Texo vaccine enhances functional OVA-specific CTL responses, compared to the OVA-Texo vaccine, and broadens CTL responses recognizing the cryptic OVA epitope in C57BL/6 mice. Furthermore, we determine that the Gag/Tat-Texo not only stimulates more efficient CTL responses than Gag-Texo, but also induces enhanced therapeutic immunity. We show that, $30 \%$ of Gag/Tat-Texo-immunized mice are free of tumor lung-metastases, compared to all Gag-Texo-immunized mice displaying lung-metastasis. In addition, the average number of tumor lung metastases colonies (32/lung) in the Gag/Tat-Texo-immunized mice was also
\end{abstract}


significantly lower than that (78/lung) observed in Gag-Texo-immunized mice. Taken together, this indicates that HIV-1 Gag/Tat-Texo capable of stimulating enhanced Gag-specific CTL responses and therapeutic immunity may become a new immunotherapeutic vaccine candidate for controlling virus in HIV-1 patients.

\section{Keywords}

Tat, T-Cell Vaccine, Gag, Exosome, CTL, Therapeutic Immunity, Transgenic HLA-A2 Mice

\section{Introduction}

HIV-1 that causes millions of deaths each year primarily acts by infecting memory $\mathrm{CD}^{+} \mathrm{CCR}^{+} \mathrm{T}$ cells, and becomes resistant to antiviral drug therapy (ART). This results in latent pro-viral reservoirs and a life-long infection [1]. As wellestablished in natural control of HIV-1 (i.e. "elite" control), potent CTLs can control it by killing virus-infected cells [2], leading to renewed interests in therapeutic vaccination for stimulating CTL responses decaying pro-viral reservoirs after pharmacologically purging the reservoirs [3]. Purging the reservoir itself is not sufficient to cause death of infected cells that remain in a resting state [4], whereas boosting CTL responses efficiently eliminates latent pro-viral reservoirs [4] [5], warranting a search for potent therapeutic vaccines.

Structural proteins of HIV-1, Gp120 and Gag, have become major targets for inducing HIV-1-specific CTL responses in vaccine development [6] [7]. Previous vaccines (peptides, DNA or viral vectors) often failed in stimulation of therapeutic immunity in $\mathrm{HIV}-1$ patients [8] possibly due to critical defects in $\mathrm{CD}^{+} \mathrm{T}$ cells and DCs [1]. Immune cell-based treatment approaches become a third pillar of therapeutics [8]. However, efficacies of DC vaccinations, which often require $\mathrm{CD} 4^{+} \mathrm{T}$ cell help [9] remain poor [10]. Functional CTL exhaustion becomes another chief issue, leading to ineffective HIV-1 control in patients [11] [12].

We previously generated an HIV-1 Gp120-specific exosome (EXO)-targeted Gp120-Texo vaccine by using ConA-T-stimulated mousepolyclonal $\mathrm{T}$ cells armed with Gp120-specific DC $\left(\mathrm{DC}_{\mathrm{Gp120}}\right)$-released EXO $\left(\mathrm{EXO}_{\mathrm{Gp120}}\right)$ [13] [14]. We demonstrated that the Gp120-Texo vaccine was more immunogenic than the $\mathrm{DC}_{\mathrm{Gp} 120}$ vaccine and was capable of stimulating $\mathrm{CD} 4^{+} \mathrm{T}$ cell-independent $\mathrm{Gp} 120$ specific CTL responses, leading to protective and long-term immunity against Gp120/HLA-A2-expressing B16 melanoma (BL6-10 $0_{\mathrm{Gp} 120 / \mathrm{A} 2}$ ) in transgenic HLAA2 mice [13] [14]. Compared to the HIV-1 structural protein Gp120, HIV-1 Gag has several important advantages as a target antigen for developing HIV-1-specific vaccines. Thus, the Gag vaccine stimulates persistent and broader CTL responses against conserved Gag epitopes in animal models [15] [16] [17]. HLAB57 HIV-1-infected individuals have also been found to have autologous CTL responses against four conserved Gag epitopes, which are associated with the 
reduced virus replication and more efficient viral control [2]. In addition, effective CTL responses against Gag have been found to correlate with the suppression of HIV-1 replication in HIV-1 patients [18] [19] [20] [21]. Since Gag has become one of the most attractive target candidates for HIV-1 vaccine development, we recently generated a Gag-specific $\mathrm{DC}\left(\mathrm{DC}_{\text {Gag }}\right)$-released EXO-targeted Gag-Texo vaccine, and demonstrated that Gag-Texo stimulated efficient Gagspecific CTL responses, leading to a complete protective immunity, but only some degree of therapeutic immunity against Gag/HLA-A2-expressing BL6$10_{\text {Gag/A2 }}$ melanoma in transgenic HLA-A2 mice [22]. Like other lentiviruses, HIV-1 encodes a trans-activating regulatory protein (Tat), which is essential for efficient transcription of the viral genome [23]. Since the HIV-1 early regulatory protein Tat possesses immunomodulatory and adjuvant properties that can be advantageous in vaccine development [23], we assumed that Tat may further enhance the immunogenicity of our Gag-Texo vaccine.

To assess our assumption, we produced recombinant adenoviruses $\mathrm{AdV}_{\text {OVA/Tat }}$ and $\mathrm{AdV}_{\text {Gag/Tat }}$ expressing OVA plus Tat and Gag plus Tat, and generated OVA/ Tat-Texo and Gag/Tat-Texo vaccines by using ConA-stimulatedmouse $\mathrm{CD} 8^{+} \mathrm{T}$ cells with the uptake of $\mathrm{AdV}_{\mathrm{OVA} / \mathrm{Tat}}$ or $\mathrm{AdV}_{\mathrm{Gag} / \mathrm{Tat}}$-transfected DC $\left(\mathrm{DC}_{\mathrm{OVA} / \mathrm{Tat}}\right.$ and $\mathrm{DC}_{\text {Gag/Tat }}$ )-released EXOs, respectively. We immunized wild-type C57BL/6 and transgenic HLA-A2 mice intravenously with the OVA/Tat-Texo or Gag/TatTexo vaccine, and assessed their ability to stimulate OVA- and Gag-specific CTL responses and immunity against OVA- and Gag/HLA-A2-expressing B16 melanoma. This demonstrated that the transgene Tat-engineered OVA/Tat-Texo vaccine not only enhanced OVA-specific CTL responses, but also broadened OVA-specific CTL responses recognizing the cryptic OVA epitope in C57BL/6 mice, compared to the OVA-Texo vaccine. In addition, the transgene Tat-engineered Gag/Tat-Texo vaccine stimulated more efficient therapeutic immunity against Gag/HLA-A2-expressing tumors in transgenic HLA-A2 mice.

\section{Materials and Methods}

\subsection{Reagents, Cell Lines and Animals}

Biotin-labeled or fluorenscein isothiocyanate (FITC)-labeled antibodies (Abs) specific for CD8 and chicken ovalbumin (OVA) antibodies (Abs) were obtained from BD Biosciences (Mississauga, Ontario, Canada). The rabbitanti-Gag and anti-Tat Polyclonal Abs were obtained from Fisher Scientific Inc., Waltham, MA. FITC-anti-CD80, FITC-anti-HLA-A2, PE-anti-CD44 and rabbit anti-CD9 Abs were obtained from BD Bioscience (Missisauga, ON, Canada). FITC-anti$\mathrm{CD11c} \mathrm{Ab}$ were purchased from Biolegend (San Diego, CA). The $\mathrm{H}-2 \mathrm{~K}^{\mathrm{b}}$-restricted OVA-specific $\mathrm{OVA}_{257-264}$ (SIINFEKL) and an irrelevant control Mut1 peptide (FEQNTAQP) [13] as well as the HLA-A2-restricted Gag $_{76-84}$ peptide (SLYNT-VATL) and an irrelevant control human epidermal growth factor receptor-2 (HER2) peptide (ILHNGAYSL) [22] were synthesized by Multiple Peptide Systems (San Diego, CA). PE-conjugated H-2K/OVA ${ }_{257-264}$ (SIINFEKL, immunodominant OVA epitope) tetramer (PE-tetramerI) was purchased from 
Beckman Coulter, Mississauga, Ontario, Canada. PE-conjugated H-2K $/ \mathrm{OVA}_{55-62}$ (KVVR-FDKI, subdominant OVA epitope) and $\mathrm{H}-2 \mathrm{~K}^{\mathrm{b}} / \mathrm{OVA}_{11-18}$ (CFDVFKEL, cryptic OVA epitope) tetramers (PE-tetramer II and III) [24] were obtained from NIH Tetramer Facility, Bethesda, MD. The highly lung-metastatic B16 melanoma cell line BL6-10 engineered to express transgene HLA-A2 and Gag forming BL6-10 $\mathrm{Gag} / \mathrm{A} 2$ cell line was previously generated in our laboratory [22]. Two gene fragments HIV-1 Gag and Tat were obtained from NIH AIDS Research and Reference Reagent Program, NIH, Bethesda, MD. Wild-type female C57BL/6 (B6) and transgenic (Tg) HLA-A2 mice $(33,584)$ were obtained from the Jackson Laboratory (Bar Harbor, MA). All mice were treated according to Animal Care Committee Guidelines of the University of Saskatchewan.

\subsection{Construction of Recombinant Adenoviruses Expressing OVA or Gag and Tat}

Recombinant adenoviral vectors $\mathrm{AdV}_{\mathrm{OVA} / \mathrm{Tat}}$ and $\mathrm{AdV}_{\mathrm{Gag} / \mathrm{Tat}}$ expressing OVA and HIV-1 Gagand Tat were constructed by inserting a fused gene fragment containing a IRES fragment (including the enhancer and poly A regions) [25], which was located between the two gene fragments OVA and Tat or Gag and Tat, into the pShuttle vector (Stratagene, La Jolla, CA) by recombinant technology. The recombinant AdV vectors were linealized by PacI digestion, and then transfected into 293 cells using Lipofectamine 2000 (Invitrogene, Carlsbad, CA) to generate $\mathrm{AdVs} \mathrm{AdV}_{\mathrm{OVA} / \mathrm{Tat}}$ or $\mathrm{AdV}_{\mathrm{Gag} / \mathrm{Tat}}$ expressing transgene OVA and Tat or Gag and Tat [26]. AdVs were amplified in 293 cells, and purified by a series of cesium chloride ultracentrifugation gradients [26].

\subsection{Dendritic Cell and Exosome Preparations}

Bone marrow-derived dendritic cells (DCs) were obtained by culturing the wildtype B6 or transgenic HLA-A2 mousebone marrow cells in culture medium containing GM-CSF $(20 \mathrm{ng} / \mathrm{ml})$ and IL-4 $(20 \mathrm{ng} / \mathrm{ml})$ for six days as previously described [22]. DCs derived from B6 and HLA-A2 mice were infected with $A_{d V}$ ovA or $\mathrm{AdV}_{\mathrm{OVA} / \mathrm{Tat}}$ and $\mathrm{AdV}_{\mathrm{Gag}}$ or $\mathrm{AdV}_{\mathrm{Gag} / \mathrm{Tat}}$, respectively, and termed $\mathrm{DC}_{\mathrm{OVA}}$ or $\mathrm{DC}_{\mathrm{OVA} / \mathrm{Tat}}$ and $\mathrm{DC}_{\mathrm{Gag}}$ or $\mathrm{DC}_{\mathrm{Gag} / \mathrm{Tat}}$. $\mathrm{DC}_{\mathrm{OVA}}, \mathrm{DC}_{\mathrm{OVA} / \mathrm{Tat}}, \mathrm{DC}_{\mathrm{Gag}}$ and $\mathrm{DC}_{\mathrm{Gag} / \mathrm{Tat}}$ released exosomes $\left(\mathrm{EXO}_{\mathrm{OVA}}, \mathrm{EXO}_{\mathrm{OVA} / \mathrm{Ta}}, \mathrm{EXO}_{\mathrm{Gag}}\right.$ and $\left.\mathrm{EXO}_{\mathrm{Gag} / \mathrm{Tat}}\right)$ were then purified from AdV-transfected DC culture supernatants by differential ultracentrifugation [22].

\subsection{OVA/Tat-Texo and Gag/Tat-Texo Preparations}

The wild-type B6 or transgenicHLA-A2 mouse splenocytes were cultured in RPMI1640 medium containing IL-2 $(20 \mathrm{U} / \mathrm{ml})$ and ConA $(1 \mu \mathrm{g} / \mathrm{ml})$ for 3 days. ConA-activated $\mathrm{CD}^{+} \mathrm{T}$ (ConA-T) cells were enriched by passage through nylon wool columns ( $\mathrm{C} \& \mathrm{~A}$ Scientific, Manassas, VA), and then purified by negative selection using anti-mouse CD8 paramagnetic beads (DYNAL Inc., Lake Success, NY). OVA-Texo or OVA/Tat-Texo and Gag-Texo or Gag/Tat-Texo vaccines were generated by incubation of ConA $(1 \mu \mathrm{g} / \mathrm{ml})$-stimulated polyclonal 
$\mathrm{CD}^{+} \mathrm{T}$ (ConA-T) cells derived from $\mathrm{B} 6$ and HLA-A2 mice with $\mathrm{EXO}_{\mathrm{OVA}}$ or $\mathrm{EXO}_{\mathrm{OVA} / \mathrm{Tat}}$ and $\mathrm{EXO}_{\mathrm{Gag}}$ or $\mathrm{EXO}_{\mathrm{Gag} / \mathrm{Tat}}$ for two hours, respectively, as previously described [13].

\subsection{Electron Microscopic Analysis}

EXOs were fixed in $4 \%$ paraformaldehyde. The pellets were then loaded onto carbon-coated formvar grids. The EXO sample-loaded grids were stained with saturated aqueous uranyl, and then examined with a JEOL 1200EX electron microscope at $60 \mathrm{kV}$.

\subsection{Western Blot Analysis}

Cell lysates (10 $\mu \mathrm{g} /$ well) were loaded onto $12 \%$ acrylamide gels, subjected to sodium dodecyl sulfate-polyacrylamide gel electrophoresis (SDS-PAGE), and subsequently transferred onto nitrocellulose membranes (Millipore, Bedford, MA). Membranes were blocked with ODYSSEY blocking buffer (LI-COR Bioscience, Lincoln, NE), immunoblotted with anti-gagAb, incubated withanti-goat IRDyeR800CW Ab, and then scanned using ODYSSEY instrument according to manufacturer's instruction (LI-COR Bioscience).

\subsection{Flow Cytometric Analysis}

DCs were stained with a panel of Abs and analyzed by flow cytometry [13]. To assess OVA/Tat-Texo- and Gag/Tat-Texo-stimulated CTL responses, the blood samples harvested from OVA/Tat-Texo-immunized B6 and Gag/Tat-Texoimmunized HLA-A2 mice ( 8 mice per group) 6 days post immunization were stained with FITC-conjugated anti-CD8 Ab (FITC-CD8) and PE-Tetramers (I, II and II), and with FITC-conjugated anti-CD8 Ab (FITC-CD8) and PE-conjugatedanti-CD44 Ab (PE-CD44), respectively, and analyzed by flow cytometry.

\subsection{Cytotoxicity Assay}

The in vivo cytotoxicity assay was performed as previously described [22]. Briefly, splenocytes were harvested from naive B6 or HLA-A2mouse spleens and incubated with either high $\left(3.0 \mu \mathrm{M}\right.$, CFSE $\left.{ }^{\text {high }}\right)$ or low $\left(0.6 \mu \mathrm{M}\right.$, CFSE $\left.{ }^{\text {low }}\right)$ concentrations of carboxy-fluorescein succinimidyl ester (CFSE), to generate differentially labeled target cells. The CFSE ${ }^{\text {high }}$ cells were pulsed with $\mathrm{OVA}_{257-264}$ or $\mathrm{Gag}_{76-84}$ peptide, whereas the $\mathrm{CFSE}^{\text {low }}$ cells were pulsed with irrelevant Mut1 or HER2 peptide, and served as internal controls. These peptide-pulsed target cells $(10 \times$ $10^{6}$ cells/mouse) were i.v. co-injected at 1:1 ratio into OVA/Tat-Texo-immunized B6 or Gag/Tat-Texo-immunized HLA-A2 mice six days after the immunization. Sixteen hours later, the residual OVA-specific or Gag-specific CFSE ${ }^{\text {high }}$ and irrelevant control CFSE ${ }^{\text {low }}$ target cells remaining in the recipients' spleens were analyzed by flow cytometry.

\subsection{Animal Studies}

To examine the therapeutic antitumor immunity conferred by Gag/Tat-Texo 
vaccine, the transgenic HLA-A2 mice (10 mice per group) were first injected i.v. with $0.5 \times 10^{6}$ BL6-10 $0_{\text {Gag } / \mathrm{A} 2}$ cells. Six days after tumor cell inoculation, HLA-A2 mice were injected i.v. with Gag/Tat-Texo or Gag-Texo $\left(2 \times 10^{6}\right.$ cells/mouse $)$. The mice were sacrificed 3 weeks after tumor cell injection, and metastatic tumor colonies were counted in lungs in a blind fashion. Metastases on freshly isolated lungs appeared as discrete black pigmented foci that were easily distinguishable from normal lung tissues and confirmed by histological examination. Metastatic foci too numerous to count were assigned an arbitrary value of $>300$.

\subsection{Statistic Analyses}

Statistical analyses were performed using the Student $t$ test for comparison of variables from different groups. A value of $p<0.05$ was considered to be statistically significant.

\section{Results}

\subsection{Generation of the Transgene Tat-Engineered OVA/Tat-Texo Vaccine}

We used a recombinant DNA technology to construct a recombinant OVA and Tat (OVA/Tat)-expressing adenovirus $\left(\mathrm{AdV}_{\mathrm{OVA} / \mathrm{Tat}}\right)$ (Figure 1). We then infected B6 mouse bone marrow-derived DCs with $\mathrm{AdV}_{\mathrm{OVA}}$ and $\mathrm{AdV}_{\mathrm{OVA} \text { /Tat }}$ to produce $\mathrm{DC}_{\mathrm{OVA}}$ and $\mathrm{DC}_{\mathrm{OVA} / \mathrm{Tat}}$. We showed that $\mathrm{DC}_{\mathrm{OVA} / \mathrm{Tat}}$ expressed cell surface $\mathrm{DC}$ marker CD11c, transgene OVA and DC maturation markers $\mathrm{Ia}^{\mathrm{b}}$ and CD80 by flow cytometry (Figure $2(\mathrm{a})$ ), indicating that $\mathrm{DC}_{\mathrm{OVA} / \mathrm{Tat}}$ are matured immunogenic DCs. $\mathrm{DC}_{\mathrm{OVA}}$ expressed similar pattern of the above molecules (data not shown). In addition, expression of cytoplasmic Tat was also confirmed in $\mathrm{DC}_{\mathrm{OVA} / \mathrm{Tat}}$ by Western blot analysis (Figure 2(b)). Following this assessment, we then purified EXOs from cell culture supernatants of $\mathrm{DC}_{\mathrm{OVA}}$ and $\mathrm{DC}_{\mathrm{OVA} / \mathrm{Tat}}$ by differential ultracentrifugation, as previously described [13]. We demonstrated by electron microscopy that EXOs had a typical exosomal characteristic of "saucer" or round shape with a diameter between 50 - $90 \mathrm{~nm}$ (Figure 2(c)), and

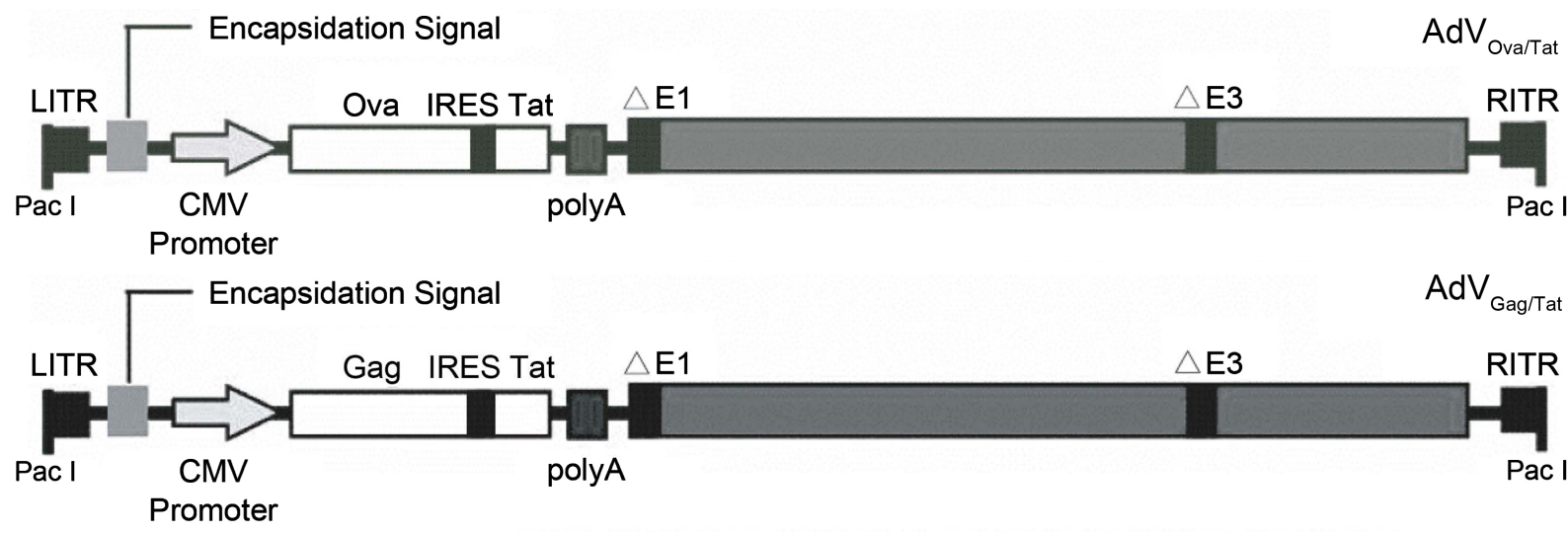

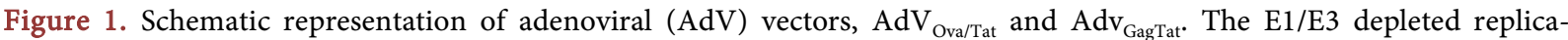
tion-deficient $\mathrm{AdV}$ is under the control of the cytomegalovirus (CMV) early/immediate promoter/enhancer. IRES, internal ribosome entry site. ITR, inverted terminal repeat. 
Western blotting revealed expression of EXO marker CD9 [27] (Figure 2(d)). We then generated the OVA-Texo and OVA/Tat-Texo vaccines using ConAstimulated $\mathrm{B} 6$ polyclonal $\mathrm{CD}^{+} \mathrm{T}$ (ConA-T) cells armed with $\mathrm{DC}_{\mathrm{OVA}^{-}}$or $\mathrm{DC}_{\text {OVA/Tat }}$-released EXOs, respectively, by incubating ConA-T cells with EXOs for 2 hours, as previously described [13].

\subsection{The Transgene Tat-Engineered OVA/Tat-Texo Vaccine Broadens and Enhances OVA-Specific CTL Responses in C57BL/6 Mice}

To assess vaccine's immunogenicity, we immunized $\mathrm{B} 6$ mice by i.v. injections with the OVA/Tat-Texo or control OVA-Texo vaccine and measured OVAspecific CTL responses six days post immunization by flow cytometry using PEtetramers (I, II and III) that recognize T cell receptors (TCRs) specific for immunodominant, subdominant and cryptic OVA epitopes, respectively. We found that the OVA/Tat-Texo vaccine stimulated more efficient CTL responses for immunodominant and subdominant OVA epitopes (2.0\% and $0.9 \%$ ), when compared to CTL responses $(1.2 \%$ and $0.3 \%)$ triggered by the OVA-Texo vaccination (Figure 3(a)). Interestingly, OVA/Tat-Texo, but not the OVA-Texo vaccine was able to stimulate some degree of CTL responses recognizing the cryptic OVA epitope (Figure 3(a)). Next, we assessed the ability of OVA/Tat-Texo to induce the differentiation of stimulated $\mathrm{CD}^{+} \mathrm{T}$ cells into effector CTLs. We adoptively transferred $\mathrm{OVA}_{257-264}$ peptide-pulsed $\mathrm{B} 6$ splenocytes that had been labeled with high concentration of CSFE (CFSE ${ }^{\text {high }}$ ), as well as the control Mut1 peptide-pulsed splenocytes that had been labeled with low concentration of CFSE (CFSE ${ }^{\text {low}}$ ) at 1:1 ratio, into recipient mice that had been vaccinated with

(a)

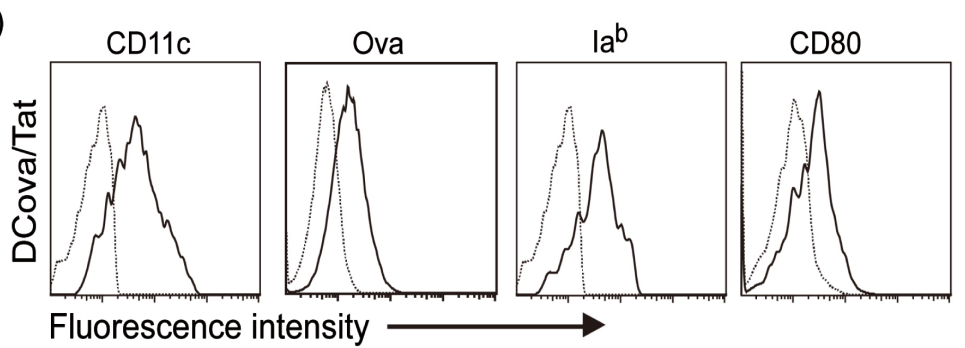

(b)

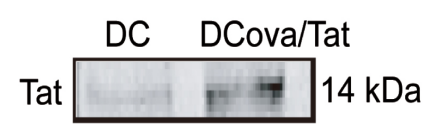

(c)

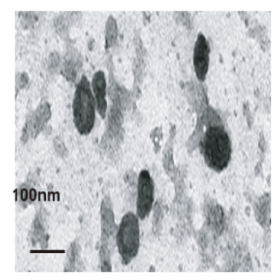

(d)

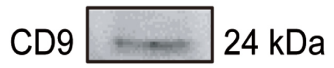

Figure 2. Phenotypic analysis of DCs and EXOs. (a) $\mathrm{DC}_{\mathrm{OVA} / \mathrm{Tat}}$ cells were stained with a panel of antibodies (Abs) (solid lines) or isotype-matched irrelevant Abs (dotted lines), and analyzed by flow cytometry. (b) Western blot analysis using lysates of $\mathrm{DC}_{\mathrm{OVA} / \mathrm{Tat}}$ and DCs and the anti-Tat Ab. (c) Electron micrograph of $\mathrm{EXO}_{\mathrm{OVA} / \mathrm{Tat}}$. Scale bar: $100 \mathrm{~nm}$. (d) Western blot analysis of $\mathrm{EXO}_{\mathrm{OVA} / \mathrm{Tat}}$ using anti-CD9 $\mathrm{Ab}$. One representative experiment of two is shown. 
(a)
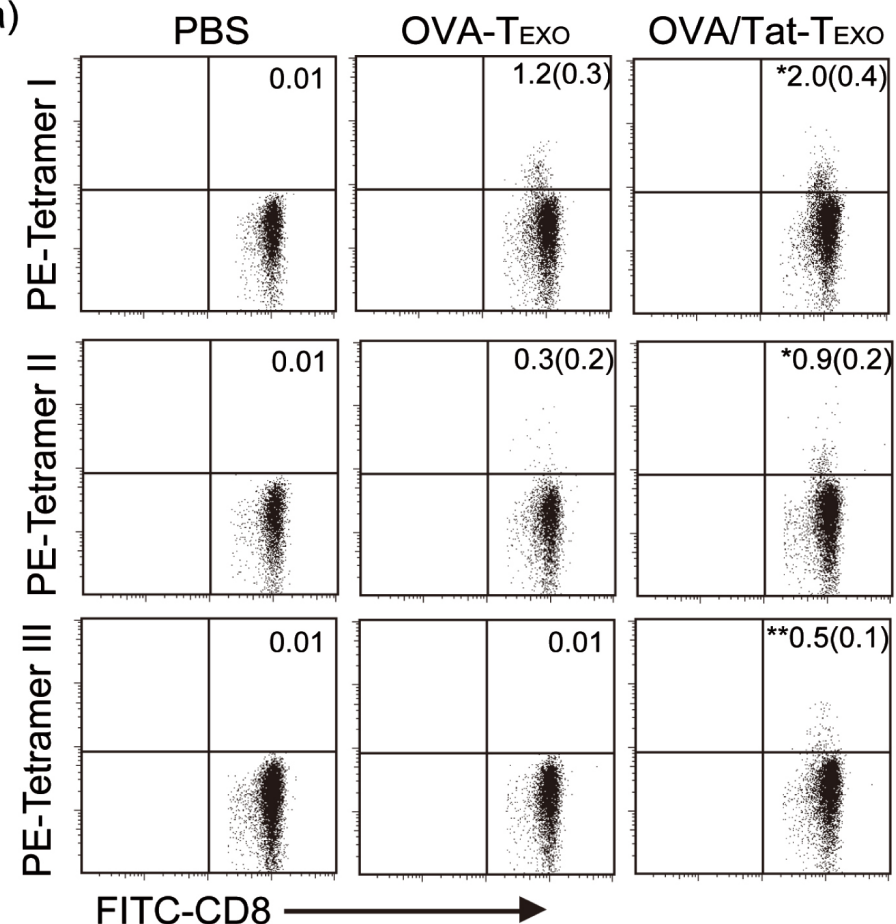

FITC-CD8

(b)

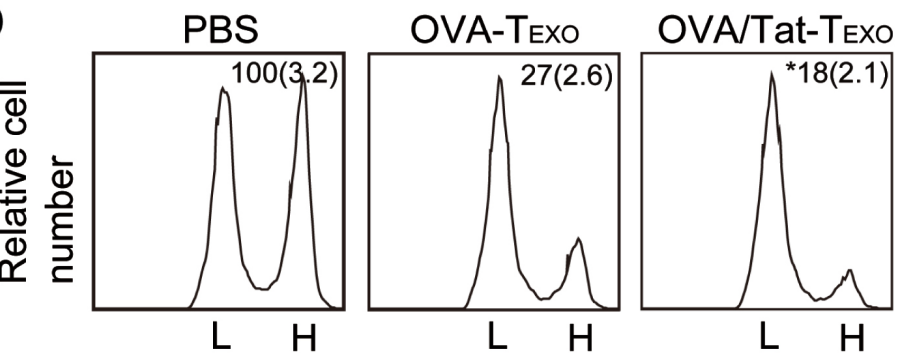

Figure 3. The OVA/Tat-Texo vaccine broadens and enhances OVAspecific CTL responses. (a) B6 mice were i.v. immunized with OVATexo, OVA/Tat-Texo or PBS. Six days after the immunization, tail blood samples of the immunized mice were stained with PE-tetramer I, PE-tetramer II or PE-tetramer III, and FITC-anti-CD8 Ab, and analyzed by flow cytometry. The value in each panel represents the percentage of $\mathrm{CD}^{+}{ }^{+}$Tetramer ${ }^{+} \mathrm{T}$ cells in the total $\mathrm{CD} 8^{+} \mathrm{T}$ cell population analyzed. (b) In vivo cytotoxicity assay. Six days after immunization, the immunized mice were i.v. injected with a mixture of $\mathrm{CFSE}^{\text {high }}$ and $\mathrm{CFSE}^{\text {low }}$-labeled splenocytes (at 1:1 ratio) that had been pulsed with OVAI and irrelevant Mut1 peptide, respectively. After $16 \mathrm{hrs}$, the spleens of immunized micewere removed, and the percentages of the residual $\mathrm{CFSE}^{\text {high }}(\mathrm{H})$ and CFSE $^{\text {low }}(\mathrm{L})$ target cells remaining in the recipients' spleens were analyzed by flow cytometry. The value in each panel represents the percentage of CFSE $^{\text {high }}$ vs. CFSE ${ }^{\text {low }}$ target cells remaining in the spleen. The value in parenthesis represents the standard deviation (SD). ${ }^{*} P<0.05$ versus cohorts of OVA-Texo. One representative experiment of two is shown.

OVA/Tat-Texo, OVA-Texo or PBS control. The transfer was performed at day 6 after immunization. Sixteen hours after the cell transfer, mouse splenocytes were analyzed by flow cytometry. Thus, the loss of OVA-specific CFSE ${ }^{\text {high }}$ target cells 
represents the OVA-specific killing activity of CTLs in immunized mice. As expected, there was a substantial loss of the CFSE ${ }^{\text {high }}$ target cells in the OVA-Texoand OVA/Tat-Texo-immunizedmice (73\% and $82 \%$ respectively) (Figure $3(\mathrm{~b})$ ), indicating that OVA/Tat-Texo-stimulated T-cells are functional effector CTLs with OVA-specific cellular cytotoxicity. This observation also showed that the OVA/Tat-Texo vaccine stimulates stronger functional CTL effector responses than the OVA-Texo vaccine in $\mathrm{B} 6$ mice.

\subsection{Generation of the Transgene Tat-Engineered Gag/Tat-Texo Vaccine}

We also constructed recombinant Gag and Tat (Gag/Tat)-expressing adenovirus $\left(\mathrm{AdV}_{\mathrm{Gag} / \mathrm{Tat}}\right)$ by using recombinant DNA technology (Figure 1). We infected transgenic HLA-A2 mouse bone marrow-derived DCs with $\mathrm{AdV}_{\mathrm{Gag}}$ and $\mathrm{AdV}_{\mathrm{Gag} / \mathrm{Tat}}$, and generated $\mathrm{DC}_{\mathrm{Gag}}$ and $\mathrm{DC}_{\mathrm{Gag} / \mathrm{Tat}}$. We showed that $\mathrm{DC}_{\mathrm{Gag} / \mathrm{Tat}}$ expressed cell surface DC marker CD11c, HLA-A2 and DC maturation markers Ia ${ }^{b}$ and CD80 by flow cytometry (Figure $4(\mathrm{a})$ ), indicating that $\mathrm{DC}_{\text {Gag/Tat }}$ are matured immunogenic DCs. DC $\mathrm{Gag}_{\text {Ga }}$ expressed a similar pattern of these molecules (data not shown). In addition, according to Western blotting analysis, $\mathrm{DC}_{\mathrm{Gag} / \mathrm{Tat}}$ also expressed cytoplasmic Gag and Tat (Figure 4(b)). EXOs from culture supernatants of $\mathrm{DC}_{\text {Gag/Tat }}$ were purified by differential ultracentrifugation, and used to generate Gag-Texo and Gag/Tat-Texo vaccines based on ConA-stimulated HLA-A2 polyclonal $\mathrm{CD}^{+} \mathrm{T}$ (ConA-T) cells armed with $\mathrm{DC}_{\mathrm{Gag}^{-}}$or $\mathrm{DC}_{\mathrm{Gag} / \mathrm{Tat}}$-released EXOs, respectively, by incubating $\mathrm{T}$ cells with EXOs for 2 hours.

\subsection{The Transgene Tat-Engineered Gag/Tat-Texo Vaccine Enhances CTL Responses in Transgenic HLA-A2 Mice}

To assess vaccine's immunogenicity, we immunized transgenic HLA-A2 mice with the Gag/Tat-Texo vaccine or the control Gag-Texo vaccine, and measured CTL responses 6 days after immunization by flow cytometry, using FITC-antiCD8 and PE-anti-CD44 antibodies for double staining [13] [14]. This approach revealed that both Gag-Texo and Gag/Tat-Texo vaccines were capable of efficient stimulation of proliferation of CTLs expressing $\mathrm{T}$ cell activation marker CD44 $(p<0.05)$ (Figure $4(c)$ ). Next, we assessed the ability of Gag/Tat-Texo to induce the differentiation of stimulated $\mathrm{CD} 8^{+} \mathrm{T}$-cells into effector CTLs. We adoptively transferred $\mathrm{Gag}_{76-84}$ peptide-pulsed splenocytes that had been strongly labeled with CSFE (CFSE ${ }^{\text {high }}$ ), as well as the control HER2 peptide-pulsed splenocytes that had been weakly labeled with CFSE $\left(\mathrm{CFSE}^{\text {low }}\right)$ at 1:1 ratio, into recipient mice that had been pre-vaccinated with either Gag/Tat-Texo or Gag-Texo. The transfer was performed at day seven following the vaccinations. Sixteen hours after the cell transfer, mouse splenocytes were analyzed by flow cytometry. We found that there was substantial loss (53\% and $68 \%)$ of the CFSE ${ }^{\text {high }}$ cells in the Gag/Tat-Texo- and Gag-Texo-immunized HLA-A2 mice (Figure 4(d)), indicating that Gag/Tat-Texo vaccine stimulated stronger functional CTL effector responses than Gag-Texo vaccine in transgenic HLA-A2 mice. 
(a)

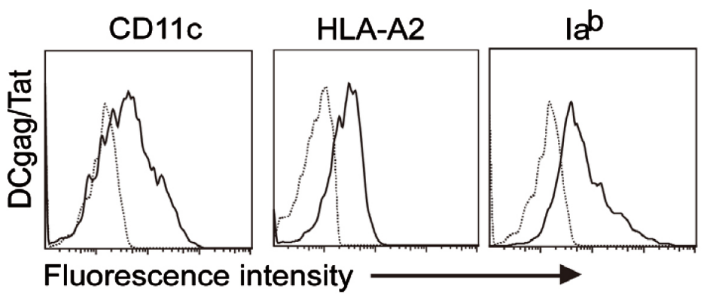

(c)

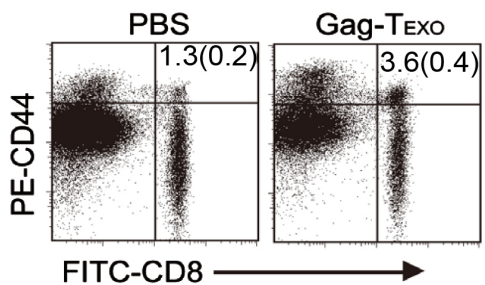

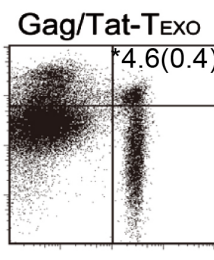

CD80

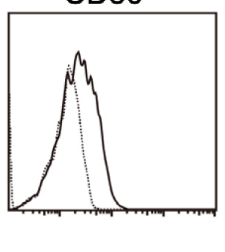

(b)

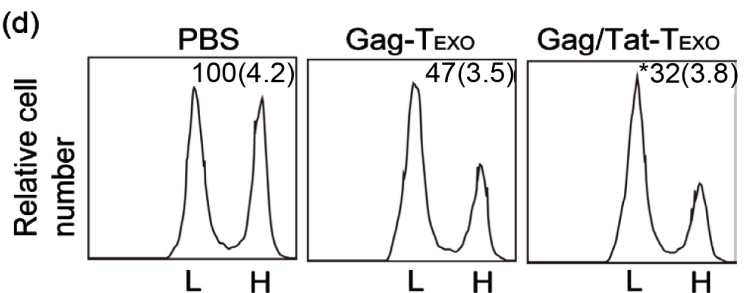

(e)

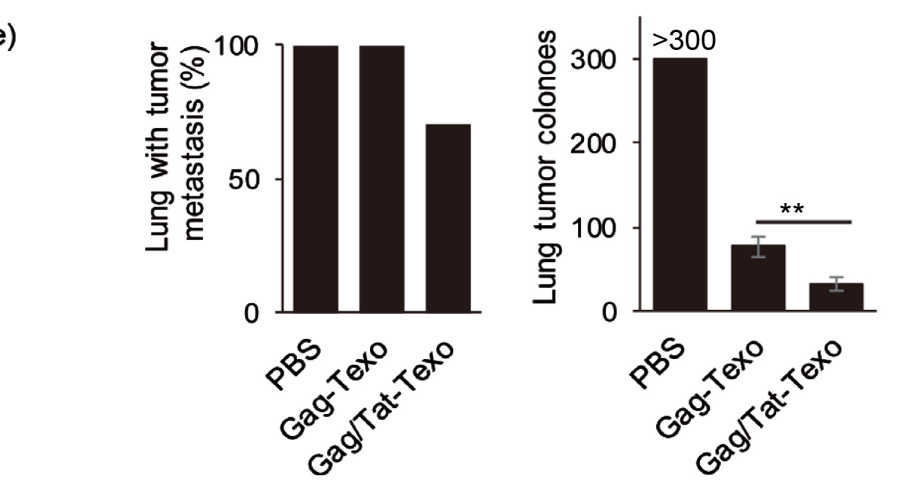

Figure 4. The Gag/Tat-Texo vaccine enhances Gag-specific CTL responses and therapeutic immunity in transgenic HLAA2 mice. (a) Phenotypic analyses of $\mathrm{DC}_{\mathrm{Gag} / \mathrm{Tat}}$. $\mathrm{DC}_{\mathrm{Gag} / \mathrm{Tat}}$ were stained with a panel of Abs (solid lines) or isotype-matched irrelevant Abs (dotted lines), and analyzed by flow cytometry. (b) Western blot analysis using lysates of DCGag/Tat and DCs and the anti-Gag and anti-Tat Abs. (c) HLA-A2 mice were i.v. immunized with Gag-Texo, Gag/Tat-Texo or PBS. Six days after the immunization, tail blood samples of the immunized mice were stained with PE-anti-CD44 and FITC-anti$\mathrm{CD} 8 \mathrm{Ab}$, and analyzed by flow cytometry. The value in each panel represents the percentage of CD ${ }^{+} \mathrm{CD} 44^{+} \mathrm{T}$ cells in the total CD8 ${ }^{+} \mathrm{T}$ cells analyzed. (d) In vivo cytotoxicity assay. Six days after immunization, the immunized mice were i.v. injected with a mixture of CFSE ${ }^{\text {high }}$ and CFSE ${ }^{\text {low }}$-labeled splenocytes (at 1:1 ratio) that had been pulsed with Gag f6-84 $_{\text {or irre- }}$ levant Mut 1 peptide, respectively. After $16 \mathrm{hrs}$, the spleens of immunized mice were removed, and the percentages of the residual $\mathrm{CFSE}^{\text {high }}(\mathrm{H})$ and $\mathrm{CFSE}^{\text {low }}(\mathrm{L})$ target cells remaining in the recipients' spleens were analyzed by flow cytometry. The value in each panel represents the percentage of CFSE $^{\text {high }}$ vs. CFSE ${ }^{\text {low }}$ target cells remaining in the spleen. (e) To assess therapeutic immunity, HLA-A2 mice were i.v. injected with BL6-10Gag/A2 melanoma cells. Six days after tumor challenge, mice were vaccinated with Gag-Texo, Gag/Tat-Texo or PBS. The mice were sacrificed 3 weeks after tumor cell challenge. The average number metastatic tumor colonies were counted in lungs. The value in parenthesis represents the standard deviation (SD). ${ }^{* *} P<0.01$ versus cohorts of Gag-Texo. One representative experiment of two is shown.

\subsection{The Transgene Tat-Engineered Gag/Tat-Texo Vaccine Enhances Gag-Specific Therapeutic Immunity in Tumor-Bearing Transgenic Mice}

To assess a potential therapeutic effect of Gag/Tat-Texo, we first challenged HLA-A2 mice with BL6-10 $0_{\mathrm{Gag} / \mathrm{A} 2}$ melanoma cells expressing cell surface HLA-A2 and cytoplasmic Gag [22]. Six days after tumor cell challenge, mice were immunized with Gag/Tat-Texo, Gag-Texo or PBS, respectively. Three weeks after tumour challenge, we found that, three out of ten (3/10) Gag/Tat-Texo-immunized mice were free of metastatic tumors in lungs, in contrast to Gag-Texo- 
immunized mice that all (10/10) carried lung tumor metastasis (Figure 4(e)). In addition, an average number (32/lung) of lung tumor colonies in seven Gag/ Tat-Texo-immunized micewas also significantly lower than that (78/lung) in Gag-Texo-immunized mice (Figure 4(e)), indicating that the Gag/Tat-Texo vaccine induces more efficient therapeutic immunity than Gag-Texo without Tat expression.

\section{Discussion}

$\mathrm{CD}^{+}$CTLs capable of recognizing some conserved and cross-strain epitopes [17] [28] play a critical role in controlling HIV-1 proliferation [29], acute phase of infection and disease progression even in the absence of neutralizing Abs [7] [30]. Dendritic cells (DCs), the most potent antigen presenting cells (APCs) capable of stimulating efficient CTL responses have been used for vaccine development [31]. DCs expressing HIV-1 Gp120 and Gag have been used as vaccines to stimulate HIV-1-specific CTL responses in animal models [32] [33]. HIV-1specific DC vaccines have been also assessed in clinical trials [33] [34]. However, these vaccines stimulated only very low levels of CTL responses and immunity in patients [35], warranting the search for other more efficient vaccination strategies.

Among HIV early regulatory proteins (Tat, Rev and Nef), Tat protein possesses immunomodulatory and adjuvant properties that can be advantageous in vaccine development [23]. For example, the Tat protein can efficiently enter DCs via binding to RGD-binding integrin receptor and activate the proteasomes, leading to increased antigen presentation and DC maturation [36] [37], direct DCs to induce predominantly Th1 responses, favoring stimulation of CTL immunity [38] and enhance, as well as broaden CTL responses to Gag and Gp120 in DNA vector- or protein-based vaccinations [39] [40] [41] [42].

We recently demonstrated that the OVA-Texo vaccine directly converted CTL exhaustion independent of the host $\mathrm{CD} 4^{+} \mathrm{T}$ cell help via its CD40L signaling activation of the mTORC1 pathway, and the Gag-Texo vaccine stimulated Gagspecific therapeutic immunity against Gag-expressing BL6-10 $0_{\text {Gag }}$ melanoma lung metastases in $\mathrm{AdV}_{\mathrm{OVA}}$-induced chronic infection [43]. In this study, we provide the first evidence that Tat enhances CTL responses and therapeutic immunity in T cell-based vaccines. We demonstrate that the transgene Tat-engineered OVA/ Tat-Texo vaccine not only enhances OVA-specific CTL responses, but also broadens their recognition to the cryptic OVA epitope. This is further supported by the evidence that Tat also enhances Gag-specific CTL responses derived from the Gag/Tat-Texo vaccination, suggesting that Gag/Tat-Texo-stimulate Gagspecific CTL responses may also eradicate HIV-1-infected cells if the vaccine is applied to HIV-1 patients. Importantly, the Gag/Tat-Texo vaccine further stimulates more efficient therapeutic immunity than Gag-Texo in transgenic HLA-A2 mice bearing 6 day-established HLA-A2/Gag-expressing BL6-10 $0_{\text {Gag/A2 }}$ melanoma lung metastases. We thus, assume that our transgene Tat-engineered EXO-targeted $\mathrm{T}$ cell-based vaccine might more efficiently convert CTL res- 
ponses and stimulate Gag-specific therapeutic immunity in chronic infection. To assess our assumption, similar vaccination experiments using the OVA/TatTexo and Gag/Tat-Texo vaccines, are underway in our laboratory in our recently described chronic infection model [43].

\section{Conclusion}

Our novel transgene Tat-engineered Gag/Tat-Texo vaccine capable of directly stimulating efficient Gag-specific CTL responses and potent therapeutic immunity in transgenic HLA-A2 mice may be useful as a new immunotherapeutic vaccine for controlling virus in HIV-1 patients with $\mathrm{CD} 4^{+} \mathrm{T}$ cell deficiency, who are being subjected to the antiviral drug therapy.

\section{Acknowledgements}

This research work was supported by a Grant from Canadian Institute of Health Research (OCH126276).

\section{Conflicts of Interest}

The authors have no financial conflicts of interest.

\section{References}

[1] Finzi, D., Blankson, J., Siliciano, J.D., et al. (1999) Latent Infection of CD4 ${ }^{+}$T Cells Provides a Mechanism for Lifelong Persistence of HIV-1, Even in Patients on Effective Combination Therapy. Nature Medicine, 5, 512-517. https://doi.org/10.1038/8394

[2] Miura, T., Brockman, M.A., Schneidewind, A., et al. (2009) HLA-B57/B`5801 Human Immunodeficiency Virus Type 1 Elite Controllers Select for Rare Gag Variants Associated with Reduced Viral Replication Capacity and Strong Cytotoxic T-Lymphocyte Recognition. Journal of Virology, 83, 2743-2755. https://doi.org/10.1128/JVI.02265-08

[3] Barouch, D.H. and Deeks, S.G. (2014) Immunologic Strategies for HIV-1 Remission and Eradication. Science, 345, 169-174. https://doi.org/10.1126/science.1255512

[4] Shan, L., Deng, K., Shroff, N.S., et al. (2012) Stimulation of HIV-1-Specific Cytolytic T Lymphocytes Facilitates Elimination of Latent Viral Reservoir after Virus Reactivation. Immunity, 36, 491-501. https://doi.org/10.1016/j.immuni.2012.01.014

[5] Deng, K., Pertea, M., Rongvaux, A., et al. (2015) Broad CTL Response Is Required to Clear Latent HIV-1 Due to Dominance of Escape Mutations. Nature, 517, 381 385. https://doi.org/10.1038/nature14053

[6] Mcmichael, A.J. (2006) HIV Vaccines. Annual Review of Immunology, 24, 227-255. https://doi.org/10.1146/annurev.immunol.24.021605.090605

[7] Titti, F., Cafaro, A., Ferrantelli, F., et al. (2007) Problems and Emerging Approaches in HIV/AIDS Vaccine Development. Expert Opinion on Emerging Drugs, 12, 23 48. https://doi.org/10.1517/14728214.12.1.23

[8] Fischbach, M.A., Bluestone, J.A. and Lim, W.A. (2013) Cell-Based Therapeutics: The Next Pillar of Medicine. Science Translational Medicine, 5, 177-179. https://doi.org/10.1126/scitranslmed.3005568

[9] Lu, W., Arraes, L.C., Ferreira, W.T. and Andrieu, J.M. (2004) Therapeutic Dendrit- 
ic-Cell Vaccine for Chronic HIV-1 Infection. Nature Medicine, 10, 1359-1365. https://doi.org/10.1038/nm1147

[10] Garcia, F., Plana, M., Climent, N., Leon, A., Gatell, J.M. and Gallart, T. (2013) Dendritic Cell Based Vaccines for HIV Infection: The Way Ahead. Human Vaccines \& Immunotherapeutics, 9, 2445-2452. https://doi.org/10.4161/hv.25876

[11] Barber, D.L., Wherry, E.J., Masopust, D., et al. (2006) Restoring Function in Exhausted CD8 T Cells during Chronic Viral Infection. Nature, 439, 682-687. https://doi.org/10.1038/nature04444

[12] Velu, V., Shetty, R.D., Larsson, M. and Shankar, E.M. (2015) Role of PD-1 Co-Inhibitory Pathway in HIV Infection and Potential Therapeutic Options. Retrovirology, 12, 14. https://doi.org/10.1186/s12977-015-0144-x

[13] Nanjundappa, R.H., Wang, R., Xie, Y., et al. (2011) GP120-Specific Exosome-Targeted T Cell-Based Vaccine Capable of Stimulating DC- and $\mathrm{CD}^{+}{ }^{+} \mathrm{T}$-Independent CTL Responses. Vaccine, 29, 3538-3547. https://doi.org/10.1016/j.vaccine.2011.02.095

[14] Nanjundappa, R.H., Wang, R., Xie, Y., Umeshappa, C.S. and Xiang, J. (2012) Novel $\mathrm{CD}^{+} \mathrm{T}$ Cell-Based Vaccine Stimulates Gp120-Specific CTL Responses Leading to Therapeutic and Long-Term Immunity in Transgenic HLA-A2 Mice. Vaccine, 30, 3519-3525. https://doi.org/10.1016/j.vaccine.2012.03.075

[15] Niu, L., Termini, J.M., Kanagavelu, S.K., et al. (2011) Preclinical Evaluation of HIV1 Therapeutic ex Vivo Dendritic Cell Vaccines Expressing Consensus Gag Antigens and Conserved Gag Epitopes. Vaccine, 29, 2110-2119.

https://doi.org/10.1016/j.vaccine.2010.12.131

[16] Li, W., Li, S., Hu, Y., Tang, B., Cui, L. and He, W. (2008) Efficient Augmentation of a Long-Lasting Immune Responses in HIV-1 Gag DNA Vaccination by IL-15 Plasmid Boosting. Vaccine, 26, 3282-3290. https://doi.org/10.1016/j.vaccine.2008.03.081

[17] Liu, Y., Li, F., Hong, K., et al. (2011) HIV Fragment Gag Vaccine Induces Broader T Cell Response in Mice. Vaccine, 29, 2582-2589. https://doi.org/10.1016/j.vaccine.2011.01.049

[18] Zuniga, R., Lucchetti, A., Galvan, P., et al. (2006) Relative Dominance of Gag p24Specific Cytotoxic T Lymphocytes Is Associated with Human Immunodeficiency Virus Control. Journal of Virology, 80, 3122-3125. https://doi.org/10.1128/JVI.80.6.3122-3125.2006

[19] Kiepiela, P., Ngumbela, K., Thobakgale, C., et al. (2007) CD8 ${ }^{+}$T-Cell Responses to Different HIV Proteins Have Discordant Associations with Viral Load. Nature Medicine, 13, 46-53. https://doi.org/10.1038/nm1520

[20] Rolland, M., Heckerman, D., Deng, W., et al. (2008) Broad and Gag-Biased HIV-1 Epitope Repertoires Are Associated with Lower Viral Loads. PLoS ONE, 3, e1424. https://doi.org/10.1371/journal.pone.0001424

[21] Julg, B., Williams, K.L., Reddy, S., et al. (2010) Enhanced Anti-HIV Functional Activity Associated with Gag-Specific CD8 T-Cell Responses. Journal of Virology, 84, 5540-5549. https://doi.org/10.1128/JVI.02031-09

[22] Wang, R., Xie, Y., Zhao, T., Tan, X., Xu, J. and Xiang, J. (2014) HIV-1 Gag-Specific Exosome-Targeted T Cell-Based Vaccine Stimulates Effector CTL Responses Leading to Therapeutic and Long-Term Immunity against Gag/HLA-A2-Expressing B16 Melanoma in Transgenic HLA-A2 Mice. Trials in Vaccinology, 3, 19-25.

[23] Caputo, A., Gavioli, R., Bellino, S., et al. (2009) HIV-1 Tat-Based Vaccines: An Overview and Perspectives in the Field of HIV/AIDS Vaccine Development. International Reviews of Immunology, 28, 285-334. 
https://doi.org/10.1080/08830180903013026

[24] Kedl, R.M., Rees, W.A., Hildeman, D.A., et al. (2000) T Cells Compete for Access to Antigen-Bearing Antigen-Presenting Cells. The Journal of Experimental Medicine, 192, 1105-1114. https://doi.org/10.1084/jem.192.8.1105

[25] Zhu, Y., Tao, M., Wu, J., et al. (2016) Adenovirus-Directed Expression of TIPE2 Suppresses Gastric Cancer Growth via Induction of Apoptosis and Inhibition of AKT and ERK1/2 Signaling. Cancer Gene Therapy, 23, 98-106. https://doi.org/10.1038/cgt.2016.6

[26] Sas, S., Chan, T., Sami, A., El-Gayed, A. and Xiang, J. (2008) Vaccination of FiberModified Adenovirus-Transfected Dendritic Cells to Express HER-2/neu Stimulates Efficient HER-2/neu-Specific Humoral and CTL Responses and Reduces Breast Carcinogenesis in Transgenic Mice. Cancer Gene Therapy, 15, 655-666. https://doi.org/10.1038/cgt.2008.18

[27] Xie, Y., Zhang, X., Zhao, T., Li, W. and Xiang, J. (2013) Natural CD8 ${ }^{+} 25^{+}$Regulatory T Cell-Secreted Exosomes Capable of Suppressing Cytotoxic T LymphocyteMediated Immunity Against B16 Melanoma. Biochemical and Biophysical Research Communications, 438, 152-155.

[28] Liu, Y., Mcnevin, J., Rolland, M., et al. (2009) Conserved HIV-1 Epitopes Continuously Elicit Subdominant Cytotoxic T-Lymphocyte Responses. Journal of Infectious Diseases, 200, 1825-1833. https://doi.org/10.1086/648401

[29] Mudd, P.A., Martins, M.A., Ericsen, A.J., et al. (2012) Vaccine-Induced CD8 ${ }^{+}$T Cells Control AIDS Virus Replication. Nature, 491, 129-133. https://doi.org/10.1038/nature11443

[30] De Rosa, S.D. and Mcelrath, M.J. (2008) T Cell Responses Generated by HIV Vaccines in Clinical trials. Current Opinion in HIV and AIDS, 3, 375-379.

[31] Palucka, K., Ueno, H. and Banchereau, J. (2011) Recent Developments in Cancer Vaccines. Journal of Immunology, 186, 1325-1331. https://doi.org/10.4049/jimmunol.0902539

[32] Van Gulck, E.R., Vanham, G., Heyndrickx, L., et al. (2008) Efficient in Vitro Expansion of Human Immunodeficiency Virus (HIV)-Specific T-Cell Responses by Gag mRNA-Electroporated Dendritic Cells from Treated and Untreated HIV Type 1Infected Individuals. Journal of Virology, 82, 3561-3573.

https://doi.org/10.1128/JVI.02080-07

[33] Villamide-Herrera, L., Ignatius, R., Eller, M., et al. (2004) Macaque Dendritic Cells Infected with SIV-Recombinant Canarypox ex Vivo induce SIV-Specific Immune Responses in Vivo. AIDS Research and Human Retroviruses, 20, 871-884. https://doi.org/10.1089/0889222041725136

[34] Ide, F., Nakamura, T., Tomizawa, M., et al. (2006) Peptide-Loaded Dendritic-Cell Vaccination Followed by Treatment Interruption for Chronic HIV-1 Infection: A Phase 1 Trial. Journal of Medical Virology, 78, 711-718. https://doi.org/10.1002/jmv.20612

[35] García, F. and Routy, J.-P. (2011) Challenges in Dendritic Cells-Based Therapeutic Vaccination in HIV-1 Infection: Workshop in Dendritic Cell-Based Vaccine Clinical Trials in HIV-1. Vaccine, 29, 6454-6463. https://doi.org/10.1016/j.vaccine.2011.07.043

[36] Gavioli, R., Gallerani, E., Fortini, C., et al. (2004) HIV-1 Tat Protein Modulates the Generation of Cytotoxic T Cell Epitopes by Modifying Proteasome Composition and Enzymatic Activity. The Journal of Immunology, 173, 3838-3843.

https://doi.org/10.4049/jimmunol.173.6.3838 
[37] Fanales-Belasio, E., Moretti, S., Nappi, F., et al. (2002) Native HIV-1 Tat Protein Targets Monocyte-Derived Dendritic Cells and Enhances Their Maturation, Function, and Antigen-Specific T Cell Responses. The Journal of Immunology, 168, 197 206. https://doi.org/10.4049/jimmunol.168.1.197

[38] Fanales-Belasio, E., Moretti, S., Fiorelli, V., et al. (2009) HIV-1 Tat Addresses Dendritic Cells to Induce a Predominant Th1-Type Adaptive Immune Response That Appears Prevalent in the Asymptomatic Stage of Infection. The Journal of Immunology, 182, 2888-2897. https://doi.org/10.4049/jimmunol.0711406

[39] Gavioli, R., Cellini, S., Castaldello, A., et al. (2008) The Tat Protein Broadens T Cell Responses Directed to the HIV-1 Antigens Gag and Env: Implications for the Design of New Vaccination Strategies against AIDS. Vaccine, 26, 727-737. https://doi.org/10.1016/j.vaccine.2007.11.040

[40] Borsutzky, S., Ebensen, T., Link, C., et al. (2006) Efficient Systemic and Mucosal Responses against the HIV-1 Tat Protein by Prime/Boost Vaccination Using the Lipopeptide MALP-2 as Adjuvant. Vaccine, 24, 2049-2056.

[41] Leroux-Roels, I., Koutsoukos, M., Clement, F., et al. (2010) Strong and Persistent $\mathrm{CD}^{+}{ }^{+} \mathrm{T}$-Cell Response in Healthy Adults Immunized with a Candidate HIV-1 Vaccine Containing gp120, Nef and Tat Antigens Formulated in Three Adjuvant Systems. Vaccine, 28, 7016-7024. https://doi.org/10.1016/j.vaccine.2010.08.035

[42] Ferrantelli, F., Maggiorella, M.T., Schiavoni, I., et al. (2011) A combination HIV Vaccine Based on Tat and Env Proteins Was Immunogenic and Protected Macaques from Mucosal SHIV Challenge in a Pilot Study. Vaccine, 29, 2918-2932. https://doi.org/10.1016/j.vaccine.2011.02.006

[43] Wang, R., Xu, A., Zhang, X., et al. (2016) Novel Exosome-Targeted T-Cell-Based Vaccine Counteracts T-Cell Anergy and Converts CTL Exhaustion in Chronic Infection via CD40L Signaling through the mTORC1 Pathway. Cellular \& Molecular Immunology, e-pub ahead of print 6 June 2016. https://doi.org/10.1038/cmi.2016.23

\section{Submit or recommend next manuscript to SCIRP and we will provide best service for you:}

Accepting pre-submission inquiries through Email, Facebook, LinkedIn, Twitter, etc. A wide selection of journals (inclusive of 9 subjects, more than 200 journals) Providing 24-hour high-quality service User-friendly online submission system Fair and swift peer-review system Efficient typesetting and proofreading procedure Display of the result of downloads and visits, as well as the number of cited articles Maximum dissemination of your research work

Submit your manuscript at: http://papersubmission.scirp.org/

Or contactwjv@scirp.org 